\title{
Cognitive Therapy for Dementia Patients: A Systematic Review
}

\author{
Carme Carrion $^{\mathrm{a}, \mathrm{b}} \quad$ Frans Folkvord $^{\mathrm{c}-\mathrm{e}}$ Dimitra Anastasiadou ${ }^{\mathrm{c}}$ \\ Marta Aymerich ${ }^{a}$
}

a UOC eHealth Center (eHC), Universitat Oberta de Catalunya (UOC), Barcelona, Spain;

beHealth Lab Research Group, Faculty of Health Sciences, Universitat Oberta de Catalunya

(UOC), Barcelona, Spain; ' Open Evidence Research, Universitat Oberta de Catalunya,

Barcelona, Spain; d Behavioural Science Institute, Radboud University, Nijmegen,

The Netherlands; ${ }^{e}$ Communication Science, University of Amsterdam, Amsterdam,

The Netherlands

\section{Keywords}

Alzheimer therapy · Dementia - Systematic review - Skills training · Reality orientation .

Cognitive therapy

\begin{abstract}
Background: Cognitive therapy is a well-established intervention for treating elderly suffering from dementia. In particular, reality orientation and skills training seem to be effective interventions for reversing cognitive impairment among elderly, although findings are inconclusive. Therefore, a systematic update of the existing evidence of cognitive therapy for people suffering from dementia is needed. Aim: To review existing scientific evidence regarding the efficacy of cognitive therapies for elderly suffering from dementia. Methods: Studies were retrieved from several bibliographic databases (January 2009 to December 2017) with prespecified selection criteria, data extraction, and methodological quality assessment. Results: In total, 10 reality orientation, 25 skills training, and 12 mixed trials were identified as meeting the inclusion criteria and were systematically reviewed. Results from reality orientation trials showed minor effects for cognitive assessments, while skills training trials and mixed trials showed contradicting effects on cognition. Effects on other outcomes (e.g., daily functioning, depression, language) were limited or not found. Conclusions: Skills training trials and mixed trials seem to affect cognitive impairment in a positive way, although the results are inconclusive. Comparison between studies was difficult due to differences in form of intervention. Because findings are inconclusive, more structuralized and comparable randomized controlled trials are needed.


Carrion et al.: Cognitive Therapy for Dementia Patients

\section{Introduction}

The prevalence of older people diagnosed with dementia is reported to be around $6 \%$ worldwide [1], and this number is projected to triple by $2050[2,3]$. Therefore, the global societal economic cost of dementia is estimated at around USD 818 billion [4]. Due to ageing population, the societal and financial burden of dementia is expected to rise in the next few decades [3]. Therefore, dementia is considered the greatest global challenge for health and social care in the current century [2], making it of great importance to assess the effectiveness of conducted therapies.

Dementia is a neuropsychiatric syndrome that is characterized by cognitive decline and progressive deterioration of daily functioning, commonly associated with behavioral and psychological symptoms of dementia (BPSD) [5]. About 5 out of every 6 dementia patients will develop some BPSD during the course of the disease [6-9]. In general, BPSD are clustered into one of five syndromes: psychosis, aggression, psychomotor agitation, depression, and apathy [6]. Studies have shown that the prevalence of BPSD is over $90 \%$ of the patients that report or show at least one of the five syndromes, which lead to multiple difficulties in daily life [10-13].

Momentarily, different pharmacological and non-pharmacological therapies are recommended to reduce the frequency and severity of BPSD, that have been shown to be effective in slowing down the impairment, especially with regard to the cognitive symptoms that are inherent to dementia [14]. In general, non-pharmacological interventions are considered as a preferable alternative to pharmacotherapy, mainly because of the adverse effects that are found in pharmacological therapies $[15,16]$. The American Psychiatric Association [17] distinguishes non-pharmacological therapies that are conducted to treat dementia into four different categories: (1) cognition-oriented treatments (e.g., reality orientation, skills training), (2) emotion-oriented treatments (e.g., supportive therapy, validation/integrated emotion-oriented care, Snoezelen, reminiscence), (3) behaviororiented treatments (behavior therapy), and (4) stimulation-oriented treatments (e.g., activity or recreational therapy, art therapy, music therapy, exercise, psychomotor therapy). There is conflicting evidence with regard to the effectiveness of non-pharmacological interventions to improve BPSD [14], which makes it necessary to have a clear overview of the existing evidence.

Because dementia is characterized by the onset of cognitive deficits that progress over time, these impairments in functional abilities of daily living have an enormous and often dramatic impact on the quality of life of both the patients and their caregivers [18]. Therefore, improving dementia patients' cognitive functioning can delay hospitalization and reduce the costs for national health care and improve patients' and carers' well-being [19]. Cognitionapproach treatments aim to redress cognitive deficits, the most prevalent and important element of suffering from dementia. Cognitive therapy is mostly theoretically driven and uses particular exercises targeting specific cognitive functions in order to optimize functioning to improve daily life [20], and has been increasingly applied to treat different symptoms that are related to dementia [21].

The current study will focus on the existing scientific evidence on cognition-oriented approaches for treating people with dementia and systematically review the findings of studies that tested their effectiveness. Reality orientation, skills training trials, and studies using a mix of these two treatments will be included. This study is an update of a previous systematic review [22], whereby randomized controlled trials (RCTs) or controlled trials using cognition-oriented approaches for treating people with dementia were analyzed until 2009. The same methodological approach will be used in this systematic review until December 2017. 
Carrion et al.: Cognitive Therapy for Dementia Patients

\section{Methods}

The search strategy to identify the key studies that we used involved using the following bibliographic databases: PubMed, Google Scholar, Cochrane Library, PsycINFO, and EMBASE. The bibliographic search included studies identified between January 2009 and December 2017 and was restricted to peer-reviewed papers written in English. Additional papers were identified by searching the reference lists of the retrieved articles, previous systematic reviews and meta-analyses.

The search strategy that was used was as follows: [dementia[majr] OR dementia [ti] OR Alzheimer[majr] OR Alzheimer[ti]] AND [psychotherapy[mh] OR psychotherapy[ti] OR cognitive therapy[mh] OR cognitive therapy [ti]] and [randomized controlled trial[pt] OR controlled clinical trial[pt] OR clinical trial[pt] OR random * [ti] OR placebo * [ti] OR blind[ti] OR blinding[ti] OR trial * OR outcome* OR randomized controlled trials [mh] OR random allocation[mh] OR double blind method[mh] OR single blind method[mh] OR clinical trials [mh] OR placebos [mh] OR outcome assessment[mh] OR outcome * [ti] OR metaanalysis[pt] OR metaanal * [ti] OR meta-anal * [ti] OR systematic review[ti, ab] OR quantitative review[ti, ab] OR quantitative overview[ti, ab] OR systematic overview[ti, ab]].

Two independent reviewers screened the search results looking for studies that were considered eligible according to the abstracts. Disagreements were resolved by consensus.

\section{Inclusion Criteria}

The inclusion criteria of this systematic review were studies that reported on intervention studies regarding cognition-oriented care approaches for dementia in older people diagnosed as having Alzheimer disease or at risk for Alzheimer disease. Only RCTs were considered eligible. Animal studies were excluded.

Data Extraction and Quality Assessment

Data extraction was performed by two reviewers. Study features and outcomes were entered into a database specifically designed for this review. Quality criteria were based on the Scottish Intercollegiate Guidelines Network (SIGN) checklists [23]. One reviewer assessed quality criteria and a second checked for accuracy. Disagreements were resolved by consensus and, if necessary, by a third reviewer. According to SIGN codes for study assessment, those trials that were clearly of an adequate quality were graded as "++" (RCTs with a very low risk of bias) or "+" (RCTs with a low risk of bias), while those of insufficient quality were graded as "-" (RCTs with a high risk of bias).

\section{Results}

By following the search strategy, we identified 1,496 records through database searching, 31 were included double. Subsequently, 1,415 records were removed after analyzing the abstracts. Finally, 81 full-text articles were assessed for eligibility by applying the inclusion/ exclusion criteria, whereby 34 articles were excluded after analyzing the full articles (not an RCT $[n=19]$, no cognitive therapy $[n=9]$, not about dementia patients or at risk for dementia $[n=5]$, or not in English $[n=1])$. The total number of trials included in the review was 47 . Quality criteria of the RCTs were based on 2008 SIGN checklists. Results that were analyzed in the current study were changes between baseline and follow-up (longest follow-up period between baseline measurement and postmeasurement reported in the study) in each condition as well as time $\times$ condition interactions. If no interaction effects were reported between condition and time, and only between-group differences were analyzed and reported, we reported these findings and included a note that only between- or within-group findings were analyzed.

The search process and total number of trials included in this review are illustrated in Figure 1. Details of all included trials are summarized in Table 1 for reality orientation interventions $(n=10)$, in Table 2 for skills training interventions $(n=25)$, and in Table 3 for mixed interventions $(n=12)$. 
Fig. 1. Flow diagram of selection of papers for inclusion in the review.

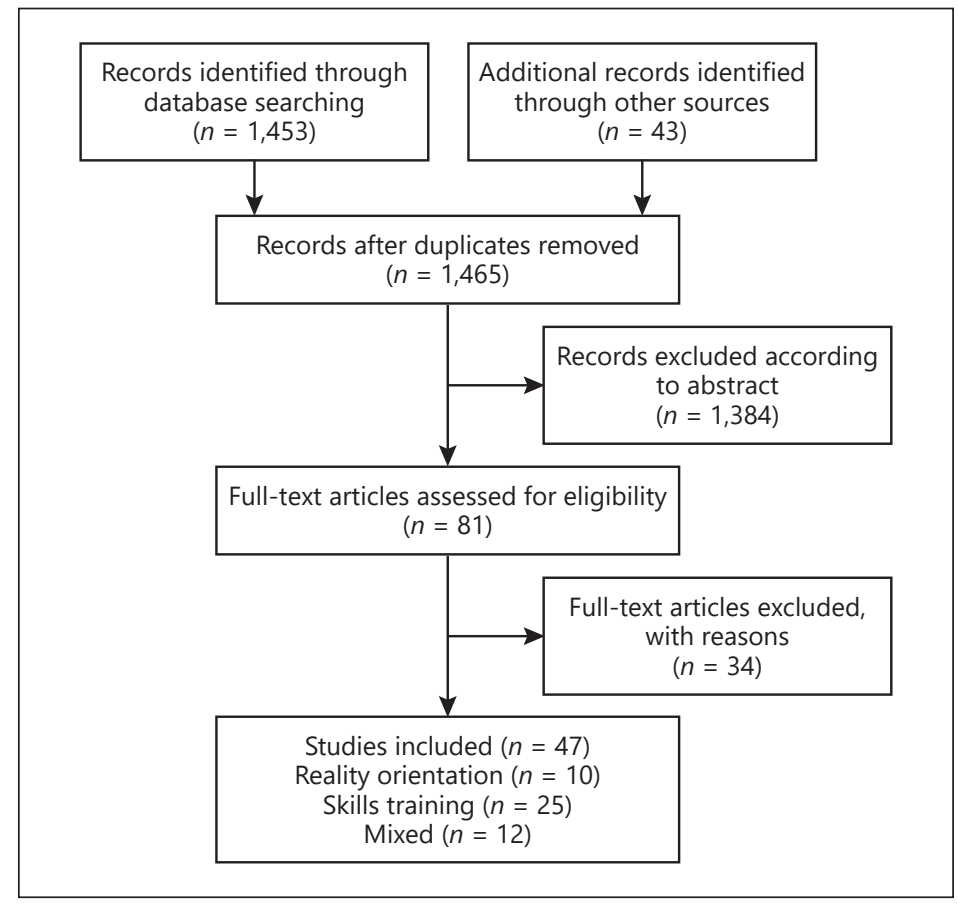

\section{Reality Orientation Trials}

Reality orientation therapy uses repeatedly the presentation and information with regard to the orientation of the patient, aiming to provide an increased understanding of their surroundings. The therapy consists of providing information about personal and current situations that are trivial for the patient's daily living, for example their name, address, date, and where the person currently is located. For the current systematic review, 10 published trials, all rated as RCT+, that assessed the effects of reality orientation were selected that met the inclusion criteria [24-33].

For reality-orientated interventions, a variation of levels of dementia was found between the studies (see also Table 1). Some studies included elderly at risk for dementia [28], elderly with mild cognitive impairments [24], patients with mild to moderate dementia [26, 30-32], diagnosed with Alzheimer disease [25, 27, 33], or a combination of these patients [29]. Assessment of cognitive impairment was mostly conducted using the Mini-Mental State Examination (MMSE) [24-27, 29-33] and the Hamilton Depression Rating Scale (HDRS) [28].

Sample sizes among the included studies ranged from 20 to 356 patients, whereby groups were not matched by level of impairment. The average patient age was above 75 years in all studies. Therapy was heterogeneous in both number and length of the sessions. For example, Cove et al. [27] conducted weekly sessions (45 min) for 14 weeks, while Alves et al. [24] conducted 3 sessions per week (60 min) for 1.5 months, while Bergamaschi et al. [26] conducted 100 sessions $(120 \mathrm{~min})$ for 1 year. The total duration of the therapy varied between studies from 6 weeks to 1 year. For the control group, most patients received treatment-asusual/usual care/no treatment, on a waitlist, except for the patients in the study by Bergamaschi et al. [26], where patients received nonspecific cognitive treatment with cholinesterase inhibitors, and in the study by Giuli etal. [29], where the patients in the control condition received general psychoeducational therapy.

As can be seen in Table 1, studies used different outcome measurements, although most studies focused on cognition, memory, daily functioning, quality of life (patient and 
Dementia

and Geriatric
Cognitive Disorders
Dement Geriatr Cogn Disord 2018;46:1-26

\begin{tabular}{l|l}
\hline DOI: 10.1159/000490851 & ( 2018 S. Karger AG, Basel \\
\hline
\end{tabular}

www.karger.com/dem

Carrion et al.: Cognitive Therapy for Dementia Patients

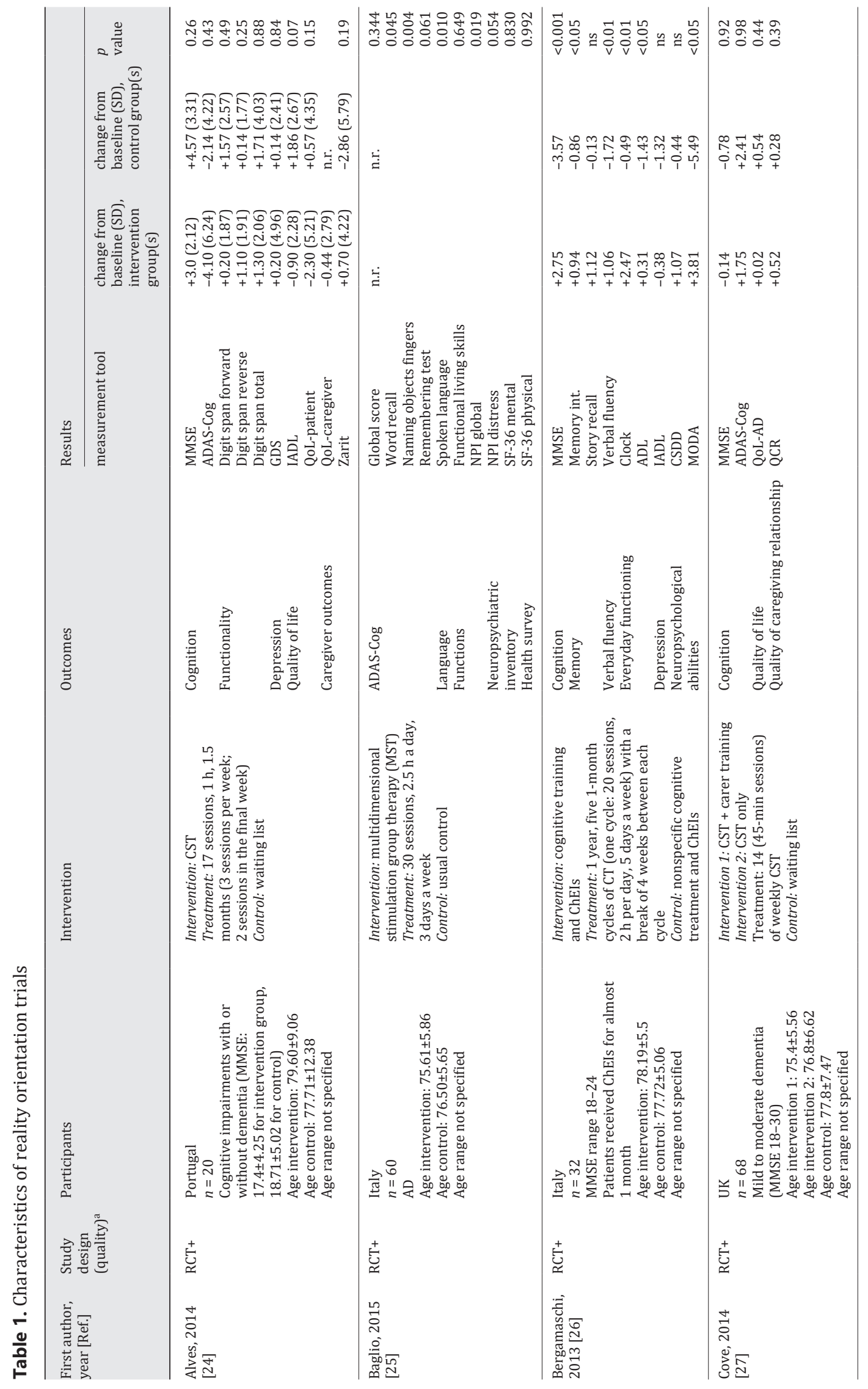


Dementia

and Geriatric
Cognitive Disorders
Dement Geriatr Cogn Disord 2018;46:1-26

\begin{tabular}{l|l}
\hline DOI: 10.1159/000490851 & (c) 2018 S. Karger AG, Basel
\end{tabular}

www.karger.com/dem

Carrion et al.: Cognitive Therapy for Dementia Patients

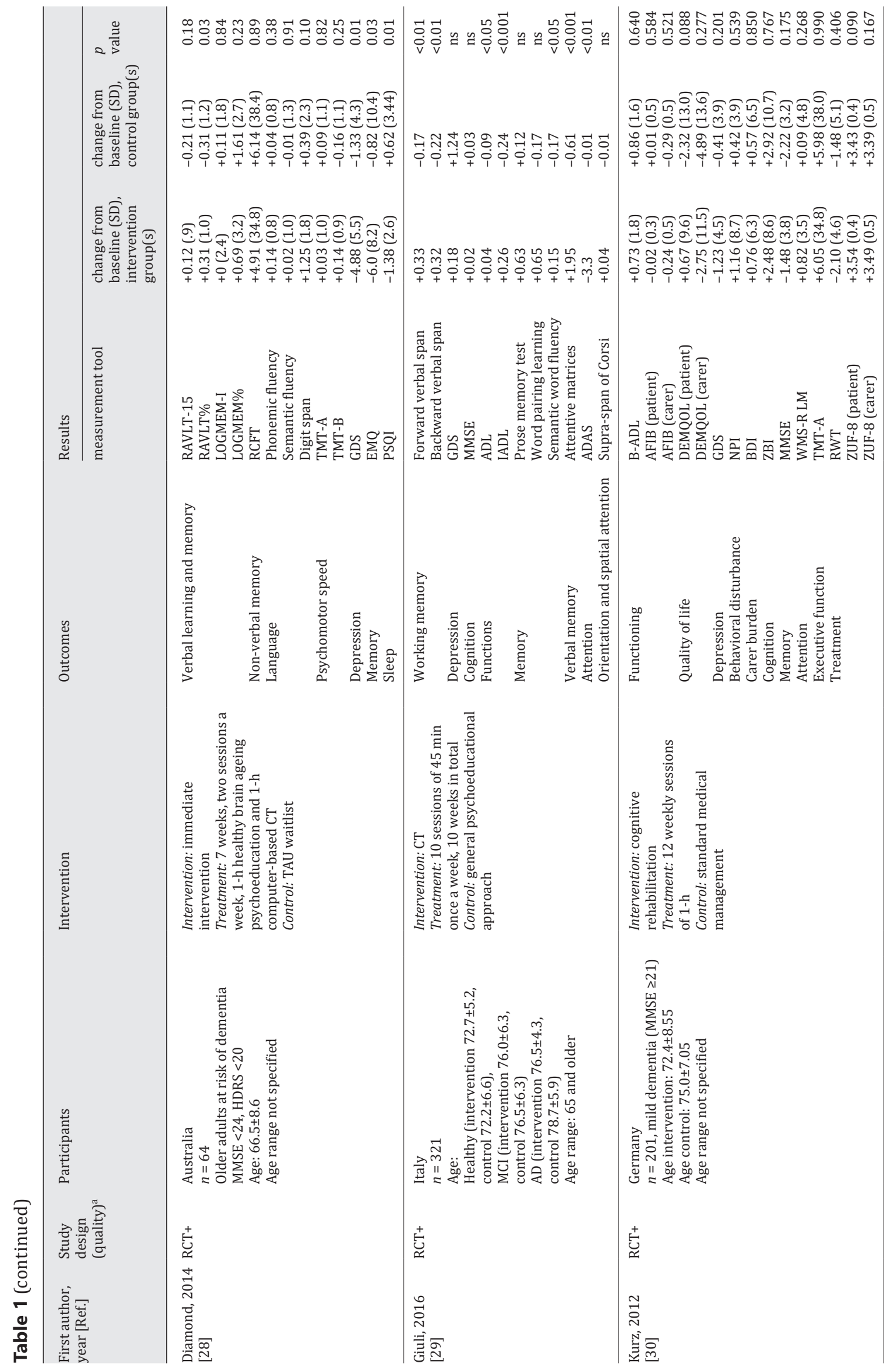


Dementia

and Geriatric
Cognitive Disorders
Dement Geriatr Cogn Disord 2018;46:1-26

\begin{tabular}{l|l}
\hline DOI: $10.1159 / 000490851$ & C 2018 S. Karger AG, Basel \\
\hline
\end{tabular}

www.karger.com/dem

Carrion et al.: Cognitive Therapy for Dementia Patients

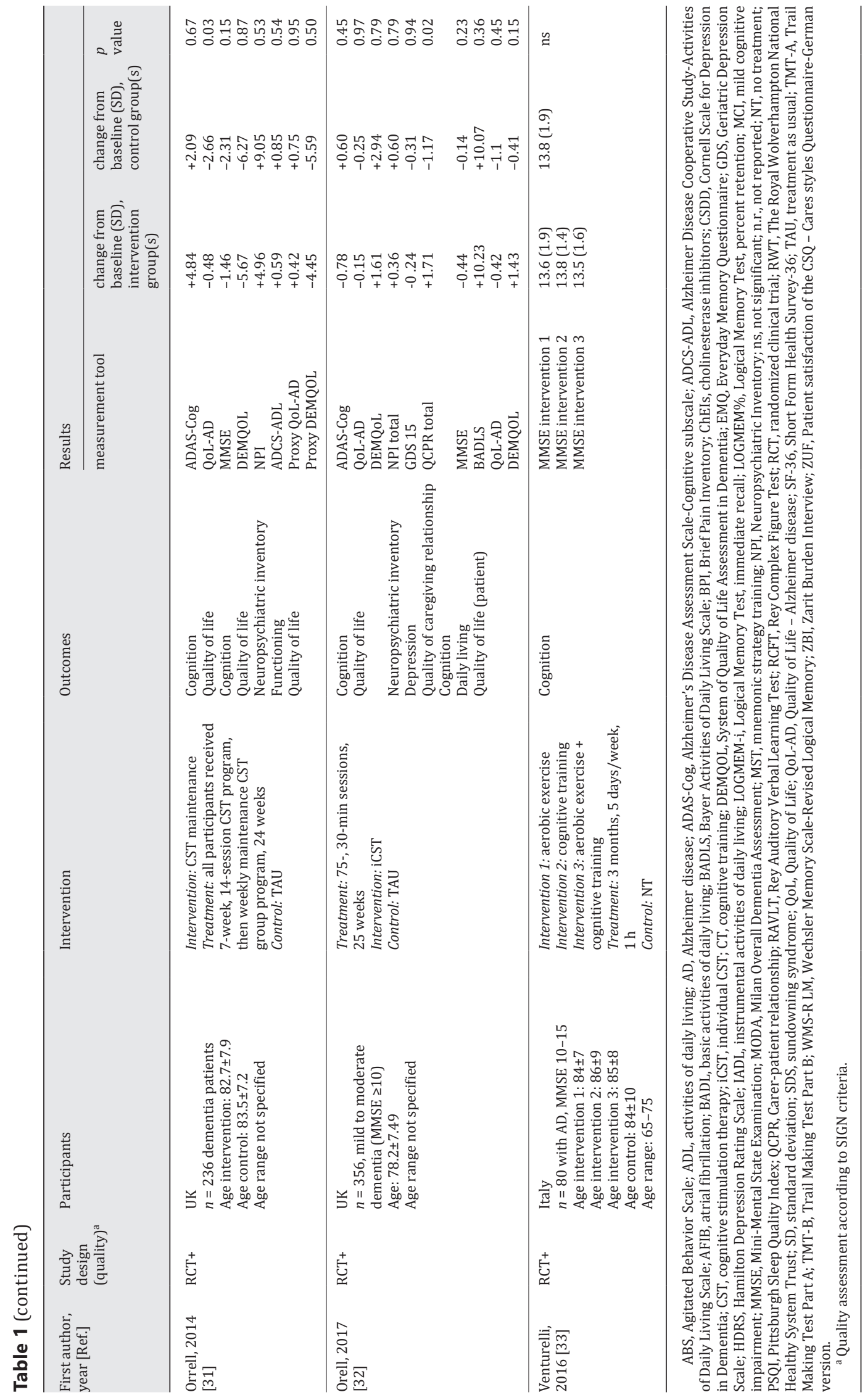



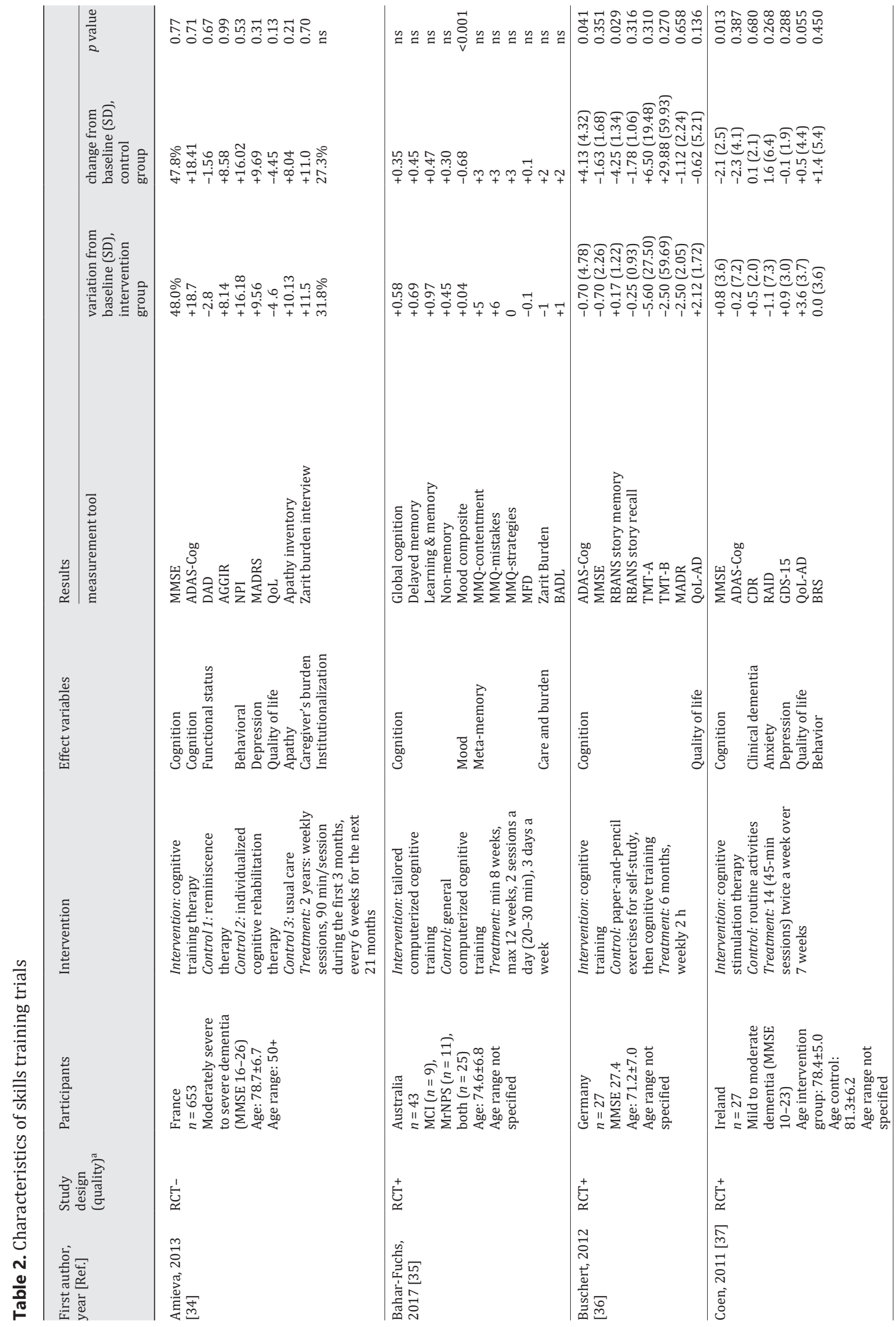
Dementia

and Geriatric
Cognitive Disorders
Dement Geriatr Cogn Disord 2018;46:1-26

\begin{tabular}{l|l}
\hline DOI: 10.1159/000490851 & ( 2018 S. Karger AG, Basel \\
\hline
\end{tabular}

www.karger.com/dem

Carrion et al.: Cognitive Therapy for Dementia Patients

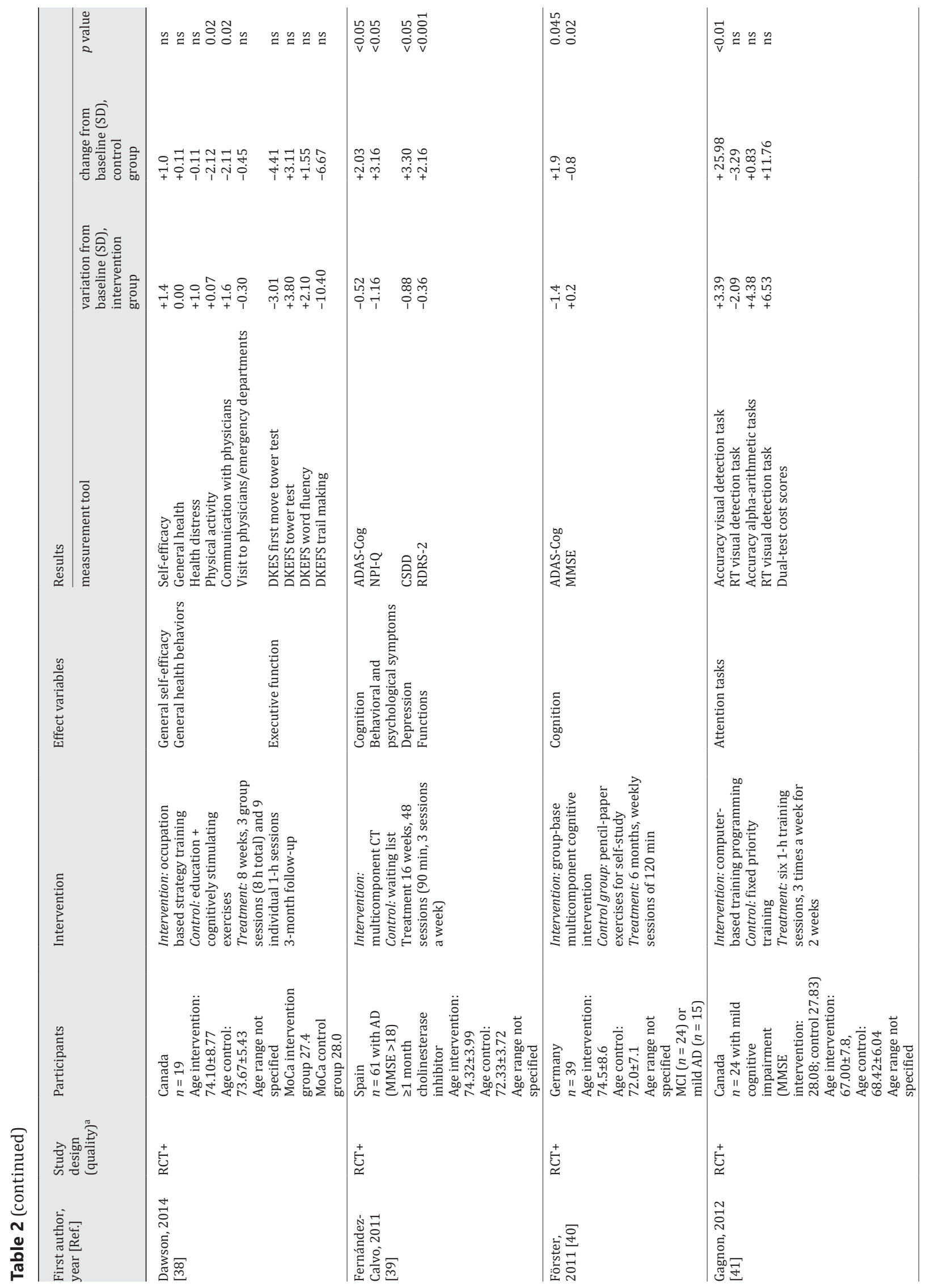


Dementia

and Geriatric
Cognitive Disorders
Dement Geriatr Cogn Disord 2018;46:1-26

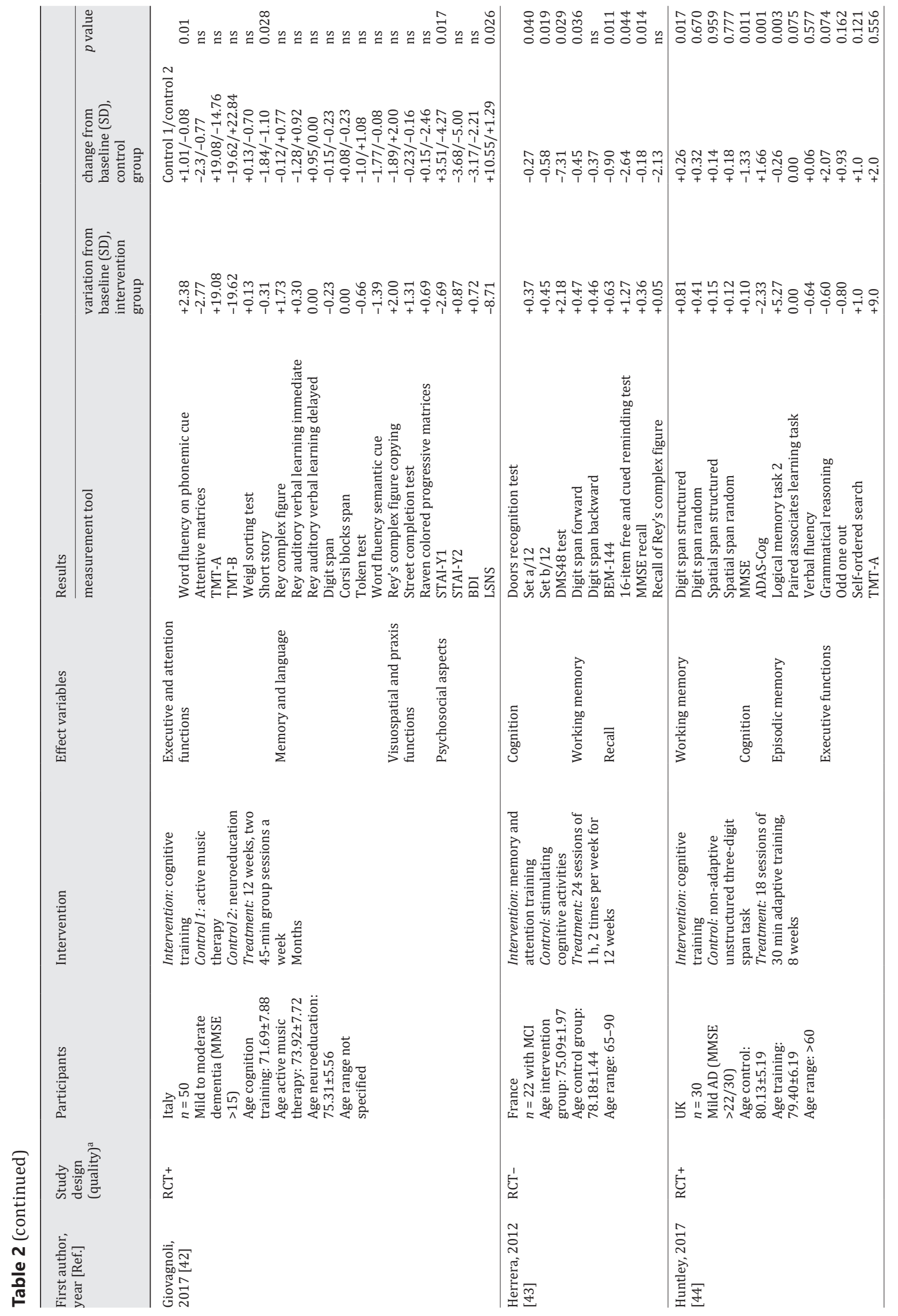


Dementia

Cognitive Disorders
Dement Geriatr Cogn Disord 2018;46:1-26

DOI: 10.1159/000490851

2018 S. Karger AG, Base

www.karger.com/dem

Carrion et al.: Cognitive Therapy for Dementia Patients

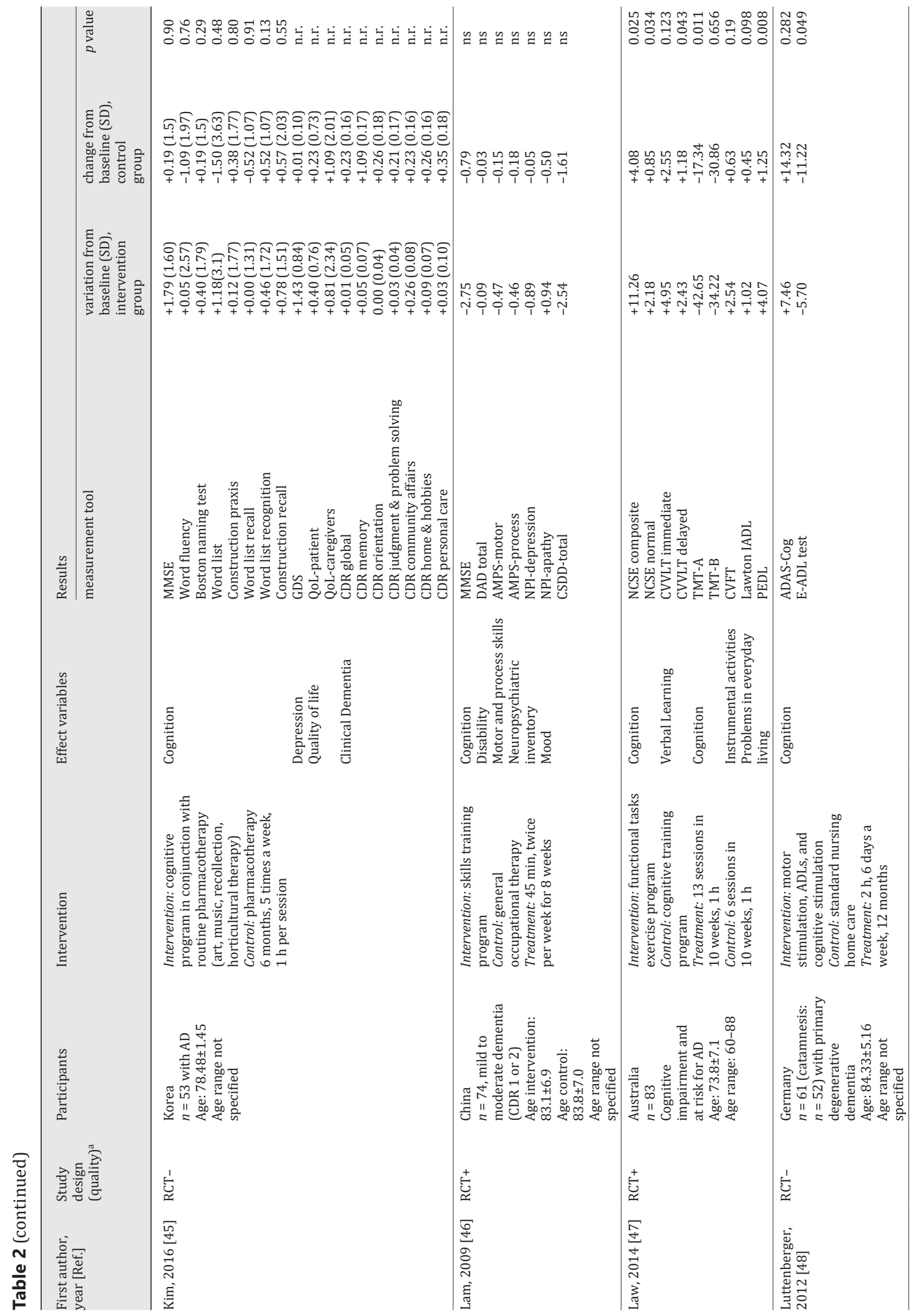


Dementia

and Geriatric
Cognitive Disorders
Dement Geriatr Cogn Disord 2018;46:1-26

\begin{tabular}{l|l}
\hline DOI: 10.1159/000490851 & (c) 2018 S. Karger AG, Basel
\end{tabular}

www.karger.com/dem

Carrion et al.: Cognitive Therapy for Dementia Patients

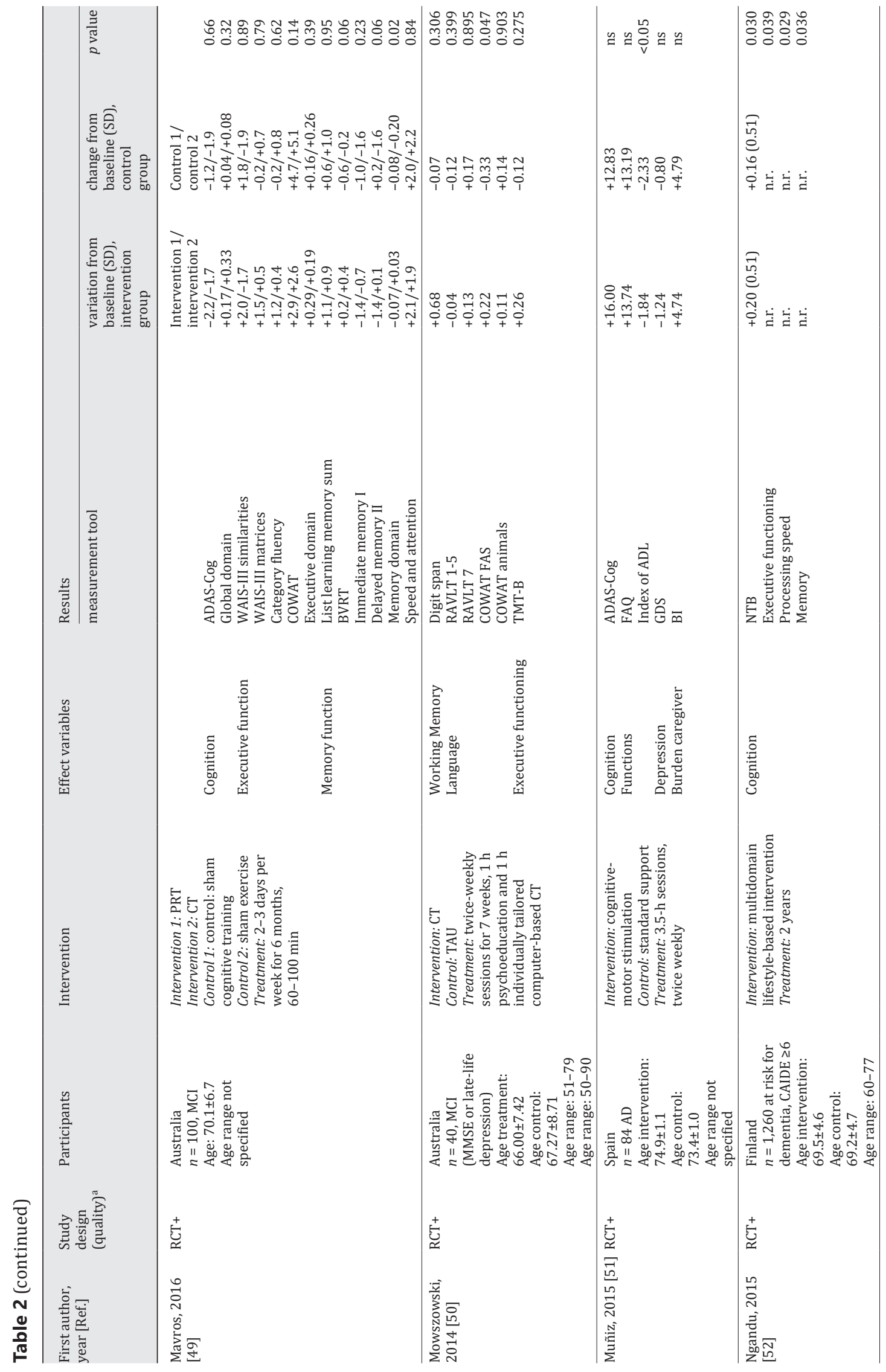


Dementia

and Geriatric
Cognitive Disorders

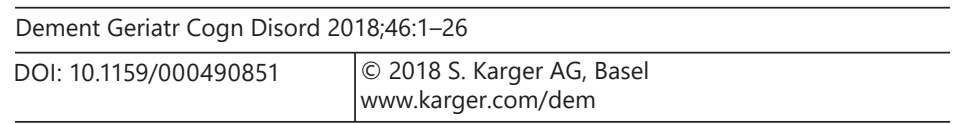

Carrion et al.: Cognitive Therapy for Dementia Patients

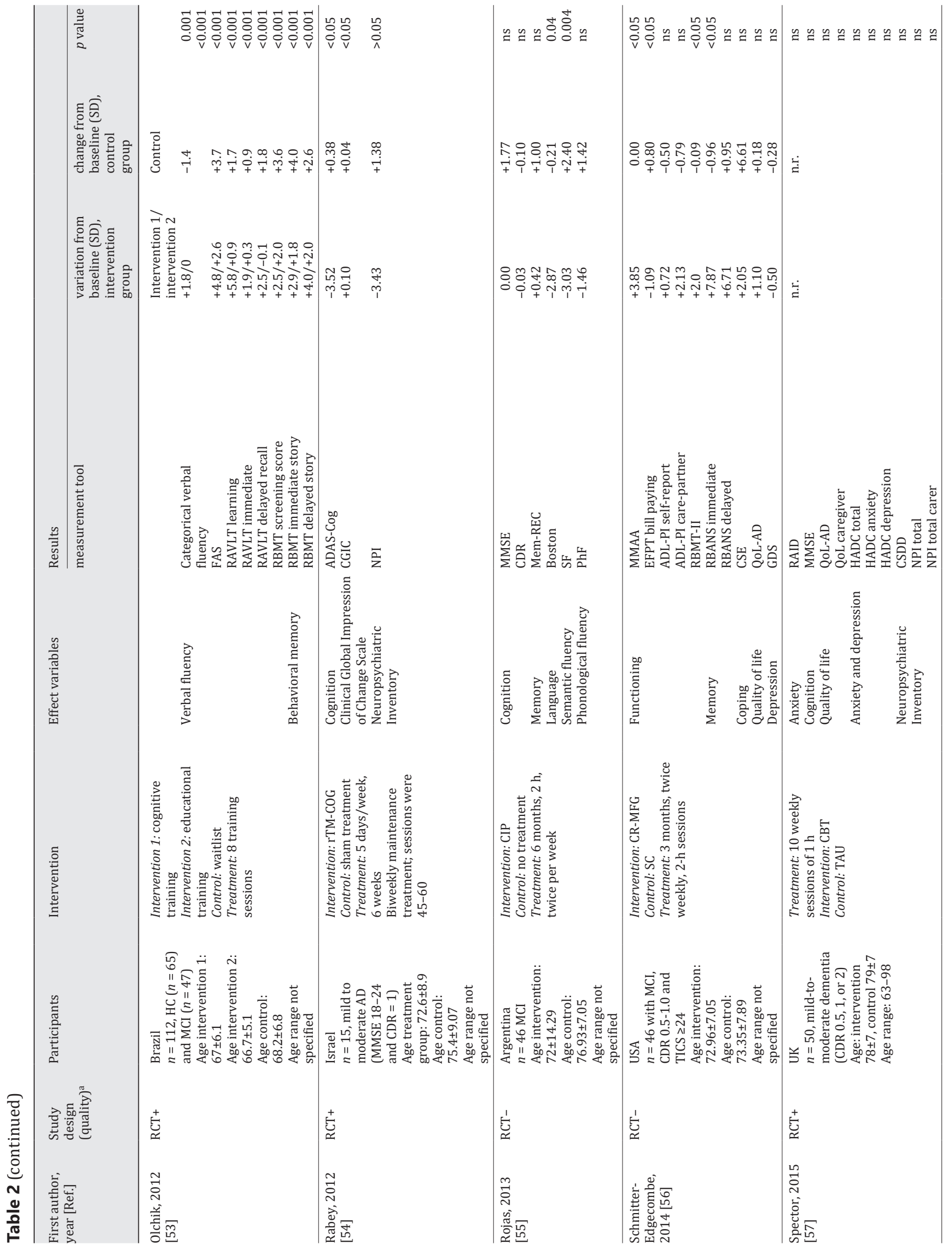


Dementia

and Geriatric
Cognitive Disorders
Dement Geriatr Cogn Disord 2018;46:1-26 DOI: 10.1159/000490851

c) 2018 S. Karger AG, Basel

www.karger.com/dem

Carrion et al.: Cognitive Therapy for Dementia Patients

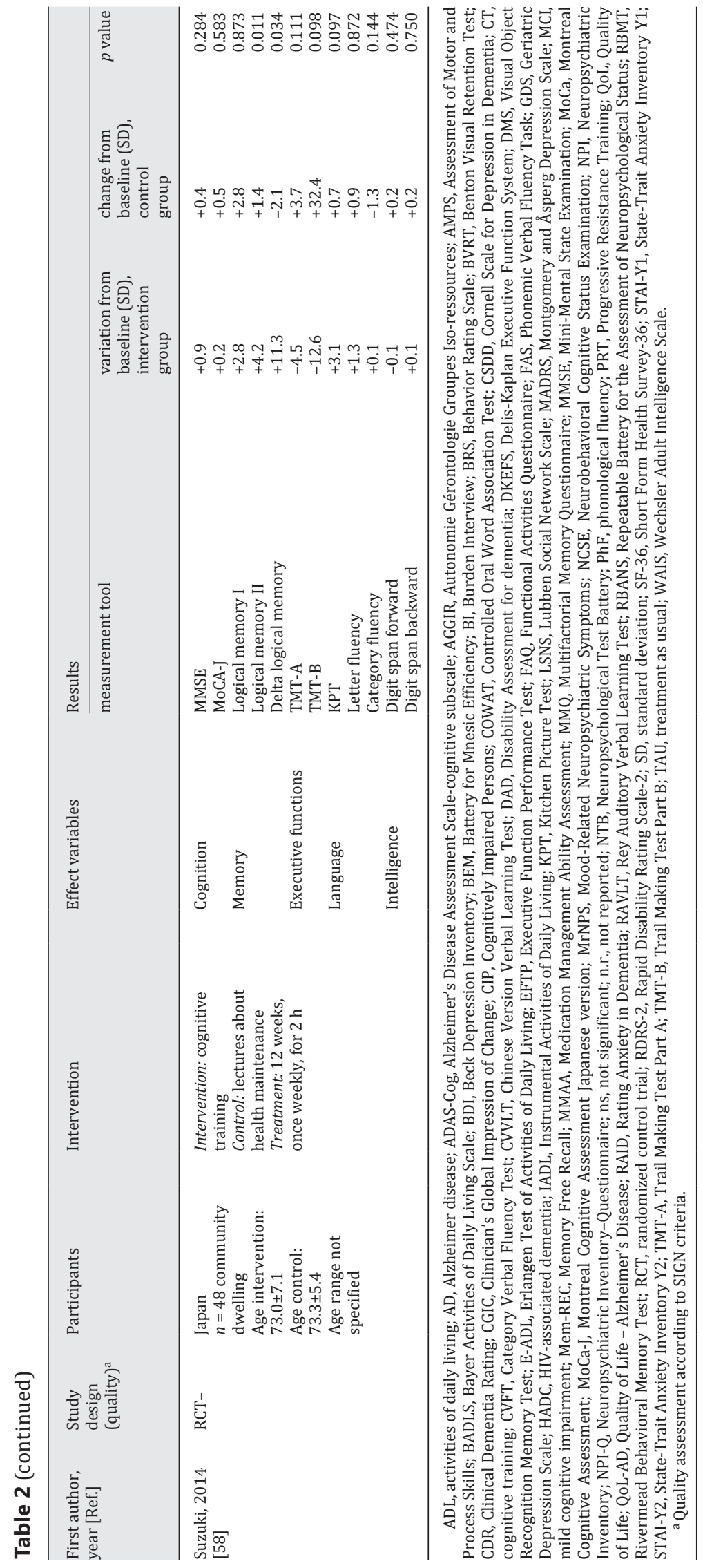


Dementia

Cognitive Disorders

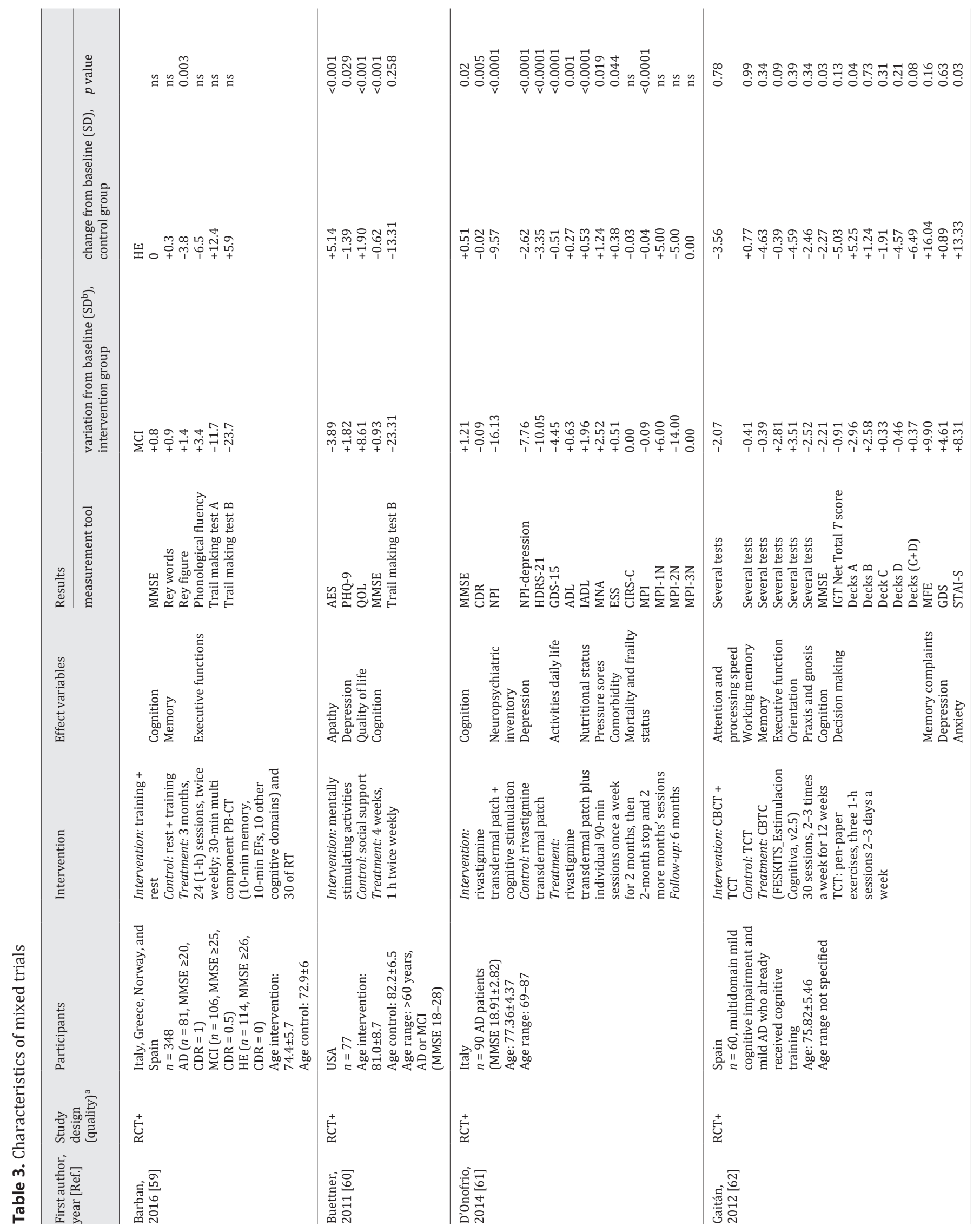




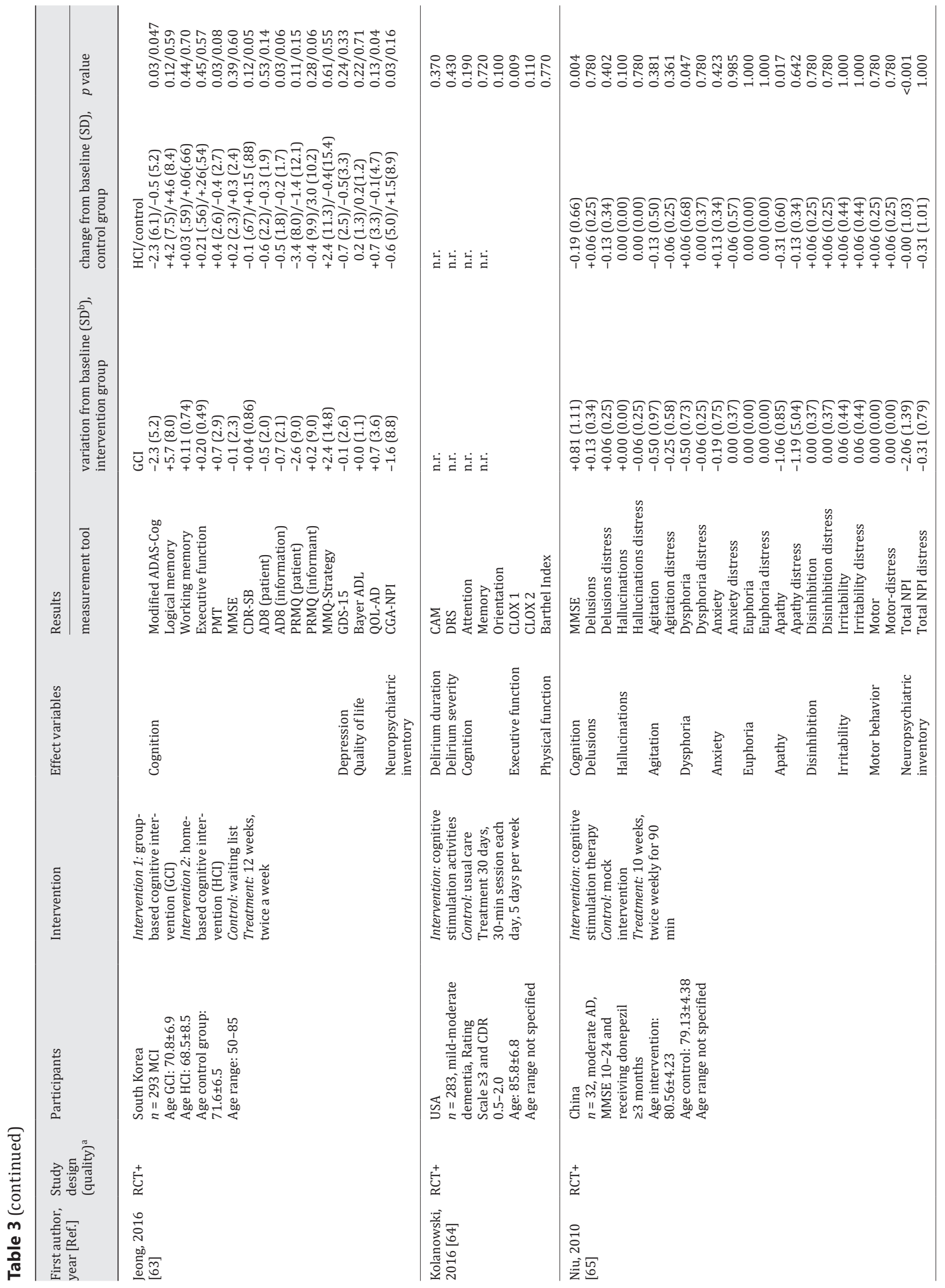


Dementia

and Geriatric
Cognitive Disorders
Dement Geriatr Cogn Disord 2018;46:1-26

DOI: 10.1159/000490851

(c) 2018 S. Karger AG, Basel
www.karger.com/dem

Carrion et al.: Cognitive Therapy for Dementia Patients

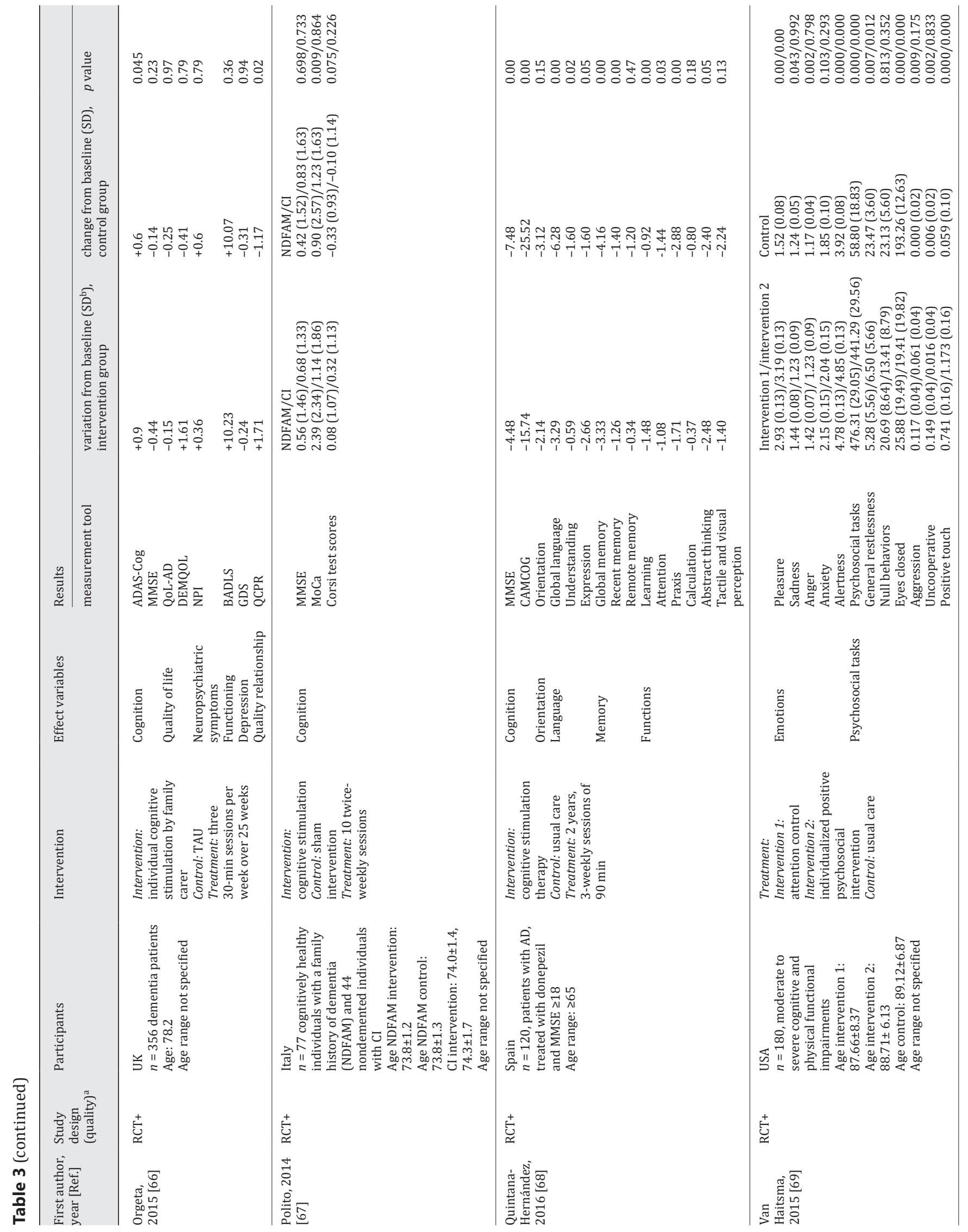



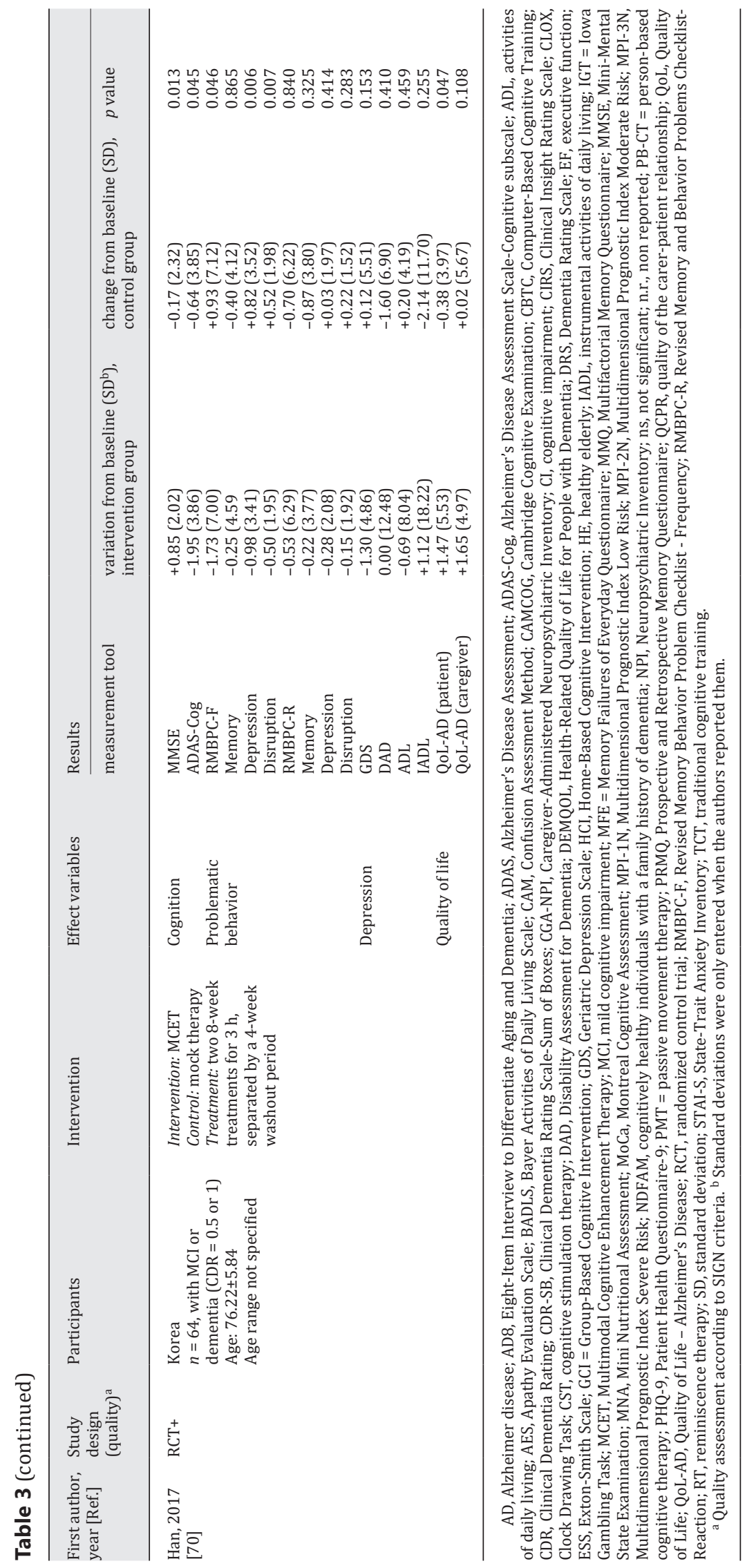
caregiver), and depression. Results showed that cognition did not differ between intervention and control in almost every study [24, 25, 27, 28, 30-33], measured with MMSE and Alzheimer's Disease Assessment Scale-Cognitive subscale (ADAS-Cog), while it did improve in the studies conducted by Bergamaschi [26] and Giuli et al. [29] (for ADAS-Cog, not for MMSE). In these studies $[26,29]$, cognition improved significantly in the intervention group, while a reduction in cognition was found in the control group. Furthermore, when focusing on individual cognitive skills such as memory skills, most studies found no effect on determinants of cognition [24, 25, 27-33] but some studies found an effect on word recall and naming objects and fingers [25], memory test with interference [26], on percent retention scores on the Rey Auditory Verbal Learning Test and everyday memory questionnaire [28], and on working memory, verbal memory, and attentive matrices [29]. Communication skills improved in the studies that examined this explicitly $[25,26]$, where most studies did not examine improvements in daily communication.

Next, almost every study found that quality of life of the patient or caregiver, or daily functioning, did not improve more than in control conditions in most studies [24, 26, 27, 30, 32], except for Orrell et al. [31, 32]. The first included study by Orrell et al. [31] found an effect for quality of life for Alzheimer disease, whereby patients in the intervention group showed less decline in quality of life than the control. The second study by Orrell et al. [32] found an increase in quality of caregiving relationship for the intervention group and a decrease for the control group. Most studies also examined the effects on depression, but no effects were found, except in the study by Diamond et al. [28], where patients reported a stronger decrease in depression than patients in the control group. The study where most of the outcomes significantly improved was also the one that had the longest intervention period [26]. Bergamaschi et al. [26] found significant effect in cognition, memory, verbal fluency, and everyday functioning. Finally, considering the quality of the studies examining reality orientation interventions, we found no important differences between the different studies. No differences were identified in terms of outcomes when studies were clustered by level of dementia.

\section{Skills Training Trials}

Skills training interventions are designed to improve patients' cognitive functioning to stop or slow down the cognitive decline that is strongly related to dementia. Multiple techniques are conducted to treat dementia patients, for example training sessions to match and categorize objects or to conduct exercises to improve daily activities. For the current systematic review, 25 published trials that assessed the effects of skills training were selected that met the inclusion criteria [34-58]. Considering their quality, we found some important differences between the different studies. Of the 25 included trials, 7 were considered RCTand 18 RCT+ (Table 2).

For skills training trials, a great variation of levels of dementia was found between the studies (Table 2). Most studies included elderly with mild cognitive impairments [35, 36, $41-43,47,49-51,53,55,56]$, some studies included elderly at risk for dementia $[38,52,58]$, some other studies patients with mild to moderate dementia $[37,46,57]$, moderate to severe dementia [34, 48], diagnosed with Alzheimer disease [39, 40, 44, 45, 48, 51, 54].

Measurement tools to assess cognitive impairment were mostly conducted with the MMSE, but also other measurements were used to assess cognitive functioning.

Sample sizes ranged from 19 to 1,260 patients, whereby groups were not matched by level of impairment. The average age of the patients was above 65 years in all studies. Therapy was heterogeneous in number, duration, and length of the sessions. For example, Amieva et al. [34] conducted treatment for 2 years, starting with weekly sessions ( $90 \mathrm{~min}$ per session), while Gagnon and Belleville [41] only conducted treatment for 2 weeks, 3 times a week (60 min per session). Control conditions varied also between studies, from active music therapy 
and neuro-education [42] to pharmacotherapy [45], waitlist [39], or pencil-paper exercises for self-study.

As can be seen in Table 2, different outcome measures were assessed, although most included studies focused on cognition, memory, language, daily functioning, quality of life (patient and caregiver), and depression. Results showed that general cognition, mostly measured by MMSE and ADAS-Cog, differed significantly between intervention and control in almost half of the studies [36, 37, 39, 40,43,44, 47, 48, 52, 54], although most studies found an effect for one measurement of cognition and not for the other, except for Förster et al. [40] and Huntley et al. [44]. In these two studies, patients of the experimental group increased their cognition relatively more than the control group after intervention, both for the ADAS-Cog and the MMSE. Other studies showed no significant differences between the conditions with regard to cognition $[34,35,45,46,49,51,55,57,58]$. Studies that used other assessment tools to measure cognitive impairment showed also positive effects. Herrera et al. [43] found an increase for the doors recognition test for the patients in the treatment condition, while the controls showed a decrease. Law et al. [47] found a stronger increase among the patients who were in the intervention group for Neurobehavioral Cognitive Status Examination (NCSE) composite and NCSE normal compared to the control, and Ngandu et al. [52] found the same for the neuropsychological test battery measurement.

Furthermore, focusing on individual cognitive skills that were assessed, like memory (e.g., meta-memory, learning memory, attentional tasks, working memory, recall, executive functioning), most studies found no or only a limited effect on determinants of cognitive functioning [34, 35, 36, 41, 42, 44-46, 50, 55]. In particular, Herrera et al. [43] found an effect on working memory and recall, where patients improved better than controls after the intervention. Law et al. [47] found a positive effect on verbal learning and on the TMT-A, whereby patients in the intervention group showed better functioning than the control, and Mavros et al. [49] found that participants of the intervention group scored relatively better on the BVRT and memory domain than control. Ngandu et al. [52] found that patients scored better at executive functioning, processing speed, and memory after the intervention compared to the control conditions. Olchik et al. [53] compared measurements with healthy controls and found that verbal fluency and behavioral memory improved significantly. Furthermore, Schmitter-Edgecombe and Dyck [56] found that patients improved some of their memory scores better than controls; the same was found by Suzuki et al. [58].

Next, almost every study found that quality of life of the patient or caregiver, or daily functioning, did not improve more in the treatment condition than in control conditions in most studies. Bahar-Fuchs et al. [35] found that mood improved more among the patients receiving treatment, Dawson et al. [38] that physical activity and communication with physicians improved more, and Giovagnoli et al. [42] found that some psychosocial aspects improved more among patients, but altogether most studies found no effect. Some studies also examined the effects on depression, but no effects were found, except in the study by Fernández-Calvo et al. [39], where patients reported a decrease in depression compared to patients in the control, who showed an increase. No relationship between the level of dementia and the final outcomes measured was seen when clustering the trials according to risk, mild, moderate, or severe dementia stages.

\section{Mixed Trials}

Some studies integrated multiple components of reality orientation and skills training in their intervention; therefore, we have decided to systematically review these trials separately. For the current systematic review, 12 published trials were selected that met the inclusion criteria [59-70] and integrated both interventions. All studies were rated as RCT+. 
For the mixed trials, a great variation of levels of dementia was found between the studies (Table 3). Some studies included elderly at risk for dementia [67], elderly with mild cognitive impairments $[63,70]$, patients with mild to moderate dementia $[64,66]$, moderate to severe dementia [69], diagnosed with Alzheimer disease [61, 62, 64, 65, 68], or a combination of these patients $[59,60]$. Assessment of cognitive impairment was mostly conducted with the MMSE, but also with other measurements (ADAS-Cog, Clinical Dementia Ranking - CDR).

Studies included samples of 32-356 patients, whereby in general groups were not matched by level of impairment. The average age of the patients was above 65 years in all studies. Therapy was heterogeneous in number, duration and length of the sessions. For example, Quintana-Hernández et al. [68] conducted treatment for 2 years, with 3-weekly sessions (90 min per session), while Buettner et al. [60] only conducted treatment for 4 weeks, two times a week ( 60 min per session). Control conditions varied also between studies, from sham intervention [67] to usual care [68] to a rivastigmine transdermal patch as control condition [61].

As can be seen in Table 3, different outcome measures were assessed, although most of the included studies focused on cognition, memory, daily functioning, quality of life (patient and caregiver), and depression.

Results showed that general cognition, mostly measured by MMSE and ADAS-Cog, differed significantly between intervention and control in most of the studies [60-63, 65, 66, $68,70]$, although some studies found an effect for one measurement of cognition and not for the other $[63,66,67]$. All effects found showed better scores for the patients that received intervention, compared to the control group. The 2-year study [68] showed significant efficacy in all measured outcomes, except for orientation, remote memory, calculation, and tactile and visual perception. Shorter studies, like the 2-month study, showed also relevant efficacy in all the measured outcomes. One study showed no significant differences between the conditions with regard to cognition [59].

Furthermore, focusing on individual cognitive skills that were assessed (e.g., memory, executive functioning, language), most studies found no or only a limited effect on determinants of cognitive functioning [59, 60,62-64]. Some studies focused on the effect of emotions, whereby for example Buettner et al. [60] and Niu et al. [65] found that patients in the intervention group showed a decrease in apathy compared to controls. Van Haitsma et al. [69] found that patients in the intervention group improved more than patients in the control group on pleasure, sadness, anger, and alertness. They also scored better on multiple psychosocial tasks. Next, some studies showed a positive effect on depression scores among patients who received intervention [60], but some studies also showed no effects [70]. The studies that assessed quality of life of the patient and the caregiver found that quality did not improve more than in control conditions in most studies, except for Han et al. [70] that found a positive effect on the quality of life of the patient (but not the caregiver). Finally, considering the quality of the studies examining mixed interventions, we found no important differences between the different studies.

\section{Discussion}

Currently, dementia is considered as one of the most prominent global health issues [71]. Cognitive therapy, more specifically reality orientation interventions, skills training programs, or a mix of both interventions, has been used extensively by therapists to treat cognitive impairment and its consequences among elderly with dementia and their caregivers [22]. The aim of the current study was to systematically review the existing evidence of the effect of cognitive therapy on dementia patients. This study is an update of the systematic review that was conducted by Carrion et al. [22]. 
Dementia

and Geriatric

Cognitive Disorders

\begin{tabular}{l|l}
\hline Dement Geriatr Cogn Disord 2018;46:1-26 \\
\hline DOI: 10.1159/000490851 & $\begin{array}{l}\text { @ 2018 S. Karger AG, Basel } \\
\text { www.karger.com/dem }\end{array}$ \\
\hline
\end{tabular}

Carrion et al.: Cognitive Therapy for Dementia Patients

This systematic research shows that using reality orientation is not effective in slowing down or improving cognitive functioning among people suffering from dementia. It is worthy to mention that only the 1-year trial showed significant effects on increasing cognition and memory, while the rest of the studies, lasting for 6 months or less, did not. In contrast, half of the trials that conducted skills training sessions and mixed interventions showed a positive effect on cognitive functioning compared to control conditions. The evidence in these studies cannot be considered as effective because most studies assessed a large battery of cognitive measurements and only found an effect on some of the measurements used. In addition, existing evidence appears to be inconclusive. It also seems relevant to consider the length of the studies that were included when analyzing skills training trials. Only the 2-year trial seems to be effective in all the assessed outcome variables. The population treated represents people at risk for dementia, so not yet suffering from it. This might also be a relevant aspect to consider, but results are not conclusive because other studies with population at risk for dementia seem not to be effective [35]. Mixed trials are also inconclusive when analyzing the length of the trial. A 2-year trial [68] achieved good final outcomes in several dimensions, but also a 2-week trial [61] seemed to be very effective. On the other hand, some other short trials do not have any efficacy, so the length does not seem to be an important aspect when analyzing intervention efficacy.

A possible explanation for the findings is that it might be that the skills training and mixed trials themselves train patients to answer cognition tests instead of improving general cognition. Compared to the previous systematic review that used the same methodological approach, on which this study was based [22], different results were found. In the previous systematic review, we [22] found an effect of reality orientation therapy but not skills training on cognitive performance, while in this study we found the opposite. It must be said that the current systematic review included more studies, most of which were well-conducted RCTs [23], while Carrion et al. [22] included less RCTs, and a large proportion of them with a great risk of bias.

Next, an increase in functional emotions and psychosocial tasks was found in some studies that focused explicitly on these aspects of dementia. For example, Van Haitsma et al. [69] found that patients in the intervention group improved more than patients in the control group on some emotional measurements and psychosocial tasks. In addition, the great majority of the included studies showed no or little effects on other outcome measurements, like quality of life (patients or caregiver), depression, language, physical activity, mood, or neuropsychiatric tasks. Finally, considering the quality of the studies examined, only RCTs with a great risk of bias were found for the skills training trials, while no important differences in the quality of experimental setup were found between the different studies for the reality-orientated interventions or mixed interventions.

Most studies included in this review had some limitations that increased the possible risk of bias. First, the disadvantage in most studies was that double-blinded randomization was not possible because patients (as well as experimenters) could be aware of the fact that they were being treated differently. Second, randomization procedures were not detailed in all studies, thereby leaving some uncertainties about the exact allocation of the participants. Third, due to the heterogeneity amongst the trials (e.g., length of treatment, duration of sessions, differences between control groups, number of participants, and severity of dementia) it is difficult to establish the exact effects of the cognitive interventions on people suffering from dementia.

In sum, evidence shows that stimulation of cognitive functions among people with dementia by skills training or a mix of reality orientation and skills training is effective in improving cognitive functioning, although the evidence is inconclusive or contradictory in most included studies. Limited evidence is found for the effect of reality orientation on 
dementia-related cognitive impairments, whereby most studies showed no effect. Next, because of the important limitations of the included studies, firm conclusions based on this systematic review cannot be drawn, and improved studies are required. Future research should aim to conduct multicenter, large sample-sized, double-blind studies with detailed randomization procedures and comparable control groups.

\section{Disclosure Statement}

The authors have no conflicts of interest to declare.

\section{References}

1 Prince M, Bryce R, Albanese E, Wimo A, Ribeiro W, Ferri CP: The global prevalence of dementia: a systematic review and metaanalysis. Alzheimers Dement 2013;9:63-75.

2 Livingston G, Sommerlad A, Orgeta V, Costafreda SG, Huntley J, Ames D, Cooper C: Dementia prevention, intervention, and care. Lancet 2017;390:2673-2734.

3 World Health Organization: Global Action Plan on the Public Health Response to Dementia 2017-2025. Geneva, World Health Organization, 2017.

4 Wimo A, Guerchet M, Ali GC, Wu YT, Prina AM, Winblad B, Prince M: The worldwide costs of dementia 2015 and comparisons with 2010. Alzheimers Dement 2017;13:1-7.

5 Abraha I, Rimland JM, Trotta FM, Dell'Aquila G, Cruz-Jentoft A, Petrovic M, Cherubini A: Systematic review of systematic reviews of non-pharmacological interventions to treat behavioural disturbances in older patients with dementia. The SENATOR-OnTop series. BMJ Open 2017;7:e012759.

6 Finkel S, Costa E, Silva J: Behavioral and psychological signs and symptoms of dementia: a consensus statement on current knowledge and implications for research and treatment. Int Psychogeriatr 1996;8:497-500.

7 Geda YE, Schneider LS, Gitlin LN, Miller DS, Smith GS, Bell J, Rosenberg PB: Neuropsychiatric symptoms in Alzheimer's disease: past progress and anticipation of the future. Alzheimers Dement 2013;9:602-608.

8 Lyketsos CG, Carrillo MC, Ryan JM, Khachaturian AS, Trzepacz P, Amatniek J, Miller DS: Neuropsychiatric symptoms in Alzheimer's disease. Alzheimers Dement 2011;7:532-539.

9 Kasl-Godley J, Gatz M: Psychosocial interventions for individuals with dementia: an integration of theory, therapy, and a clinical understanding of dementia. Clin Psychol Rev 2000;20:755-782.

10 Cohen D, Eisdorfer C, Gorelick P, Paveza G, Luchins DJ, Freels S, Ashford JW, Semla T, Levy P, Hirschman R: Psychopathology associated with Alzheimer's disease and related disorders. J Gerontol 1993;48:M255-M260.

11 Fernández M, Gobartt AL, Balañá M: Behavioural symptoms in patients with Alzheimer's disease and their association with cognitive impairment. BMC Neurol 2010;10:87.

12 Marin DB, Green CR, Schmeidler J, Harvey PD, Lawlor BA, Ryan TM, Aryan M, Davis KL, Mohs RC: Non cognitive disturbances in Alzheimer's disease: frequency, longitudinal course, and relationship to cognitive symptoms. J Am Geriatr Soc 1997;45:1331-1338.

13 Zubenko GS, Zubenko WN, McPherson S, Spoor E, Marin DB, Farlow MR, Smith GE, Geda YE, Cummings JL, Petersen RC, et al: A collaborative study of the emergence and clinical features of the major depressive syndrome of Alzheimer's disease. Am J Psychiatry 2003;160:857-866.

14 Legere LE, McNeill S, Martin LS, Acorn M, An D: Non-pharmacological approaches for behavioural and psychological symptoms of dementia in older adults: a systematic review of reviews. J Clin Nurs DOI: 10.1111/ jocn.14007.

15 Bierman EJ, Comijs HC, Gundy CM, Sonnenberg C, Jonker C, Beekman AT: The effect of chronic benzodiazepine use on cognitive functioning in older persons: good, bad or indifferent? Int J Geriatr Psychiatry 2007;22:11941200.

16 Maher AR, Maglione M, Bagley S, Suttorp M, Hu JH, Ewing B, Wang Z, Timmer M, Sultzer D, Shekelle PG: Efficacy and comparative effectiveness of atypical antipsychotic medications for off-label uses in adults: a systematic review and meta-analysis. JAMA 2011;306:1359-1369.

17 American Psychiatric Association American Psychiatric Association Practice Guidelines for the treatment of psychiatric disorders: compendium 2006. Washington, American Psychiatric Association, 2006.

18 Andersen CK, Wittrup-Jensen, KU, Lolk A, Andersen K, Kragh-Sørensen P: Ability to perform activities of daily living is the main factor affecting quality of life in patients with dementia. Health Qual Life Outcomes 2004;2: 52.

19 Graff MJ, Adang EM, Vernooij-Dassen MJ, Dekker J, Jönsson L, Thijssen M, Rikkert MGO: Community occupational therapy for older patients with dementia and their caregivers: cost effectiveness study. BMJ 2008;336: 134-138.

20 Kasl-Godley J, Gatz M: Psychosocial interventions for individuals with dementia: an integration of theory, therapy, and a clinical understanding of dementia. Clin Psychol Rev 2000;20:755-782. 
21 Huntley JD, Gould RL, Liu K, Smith M, Howard RJ: Do cognitive interventions improve general cognition in dementia? A meta-analysis and meta-regression. BMJ Open 2015;5:e005247.

22 Carrion C, Aymerich M, Baillés E, López-Bermejo A: Cognitive psychosocial intervention in dementia: a systematic review. Dement Geriatr Cogn Disord 2013;36:363-375.

23 Scottish Intercollegiate Guidelines Network (SIGN): SIGN 50: A Guideline Developer's Handbook. Edinburgh, Scottish Intercollegiate Guidelines Network, 2008.

24 Alves J, Alves-Costa F, Magalhães R, Gonçalves ÓF, Sampaio A: Cognitive stimulation for Portuguese older adults with cognitive impairment: a randomized controlled trial of efficacy, comparative duration, feasibility, and experiential relevance. Am J Alzheimers Dis Other Demen 2014;29:503-512.

25 Baglio F, Griffanti L, Saibene FL, Ricci C, Alberoni M, Critelli R, Villanelli F, Fioravanti R, Mantovani F, D’amico A, Cabinio M, Preti MG, Nemni R, Farina E: Multi stimulation group therapy in Alzheimer's disease promotes changes in brain functioning. Neurorehabil Neural Repair 2015;29:13-24.

26 Bergamaschi S, Arcara G, Calza A, Villani D, Orgeta V, Mondini S: One-year repeated cycles of cognitive training (CT) for Alzheimer's disease. Aging Clin Exp Res 2013;25:421-426.

27 Cove J, Jacobi N, Donovan H, Orrell M, Stott J, Spector A: Effectiveness of weekly cognitive stimulation therapy for people with dementia and the additional impact of enhancing cognitive stimulation therapy with a carer training program. Clin Interv Aging 2014; 9:2143.

28 Diamond K, Mowszowski L, Cockayne N, Norrie L, Paradise M, Hermens DF, Naismith SL: Randomized controlled trial of a healthy brain ageing cognitive training program: effects on memory, mood, and sleep. J Alzheimers Dis 2015;44:1181-1191.

29 Giuli C, Papa R, Lattanzio F, Postacchini D: The effects of cognitive training for elderly: results from My Mind Project. Rejuvenation Res 2016;19:485-494.

30 Kurz A, Thöne-Otto A, Cramer B, Egert S, Frölich L, Gertz HJ, Werheid K; CORDIAL: cognitive rehabilitation and cognitive-behavioral treatment for early dementia in Alzheimer disease: a multicenter, randomized, controlled trial. Alzheimer Dis Assoc Disord 2012;26:246-253.

31 Orrell M, Aguirre E, Spector A, Hoare Z, Woods RT, Streater A, Russell I: Maintenance cognitive stimulation therapy for dementia: single blind, multicenter, pragmatic randomized controlled trial. Br J Psychiatry 2014; 204:454-461.

32 Orrell M, Yates L, Leung P, Kang S, Hoare Z, Whitaker C, Pearson S: The impact of individual Cognitive Stimulation Therapy (iCST) on cognition, quality of life, caregiver health, and family relationships in dementia: a randomized controlled trial. PLoS Med 2017;14:e1002269.

33 Venturelli M, Sollima A, Cè E, Limonta E Bisconti AV, Brasioli A, Esposito F: Effectiveness of exercise- and cognitive-based treatments on salivary cortisol levels and sun downing syndrome symptoms in patients with Alzheimer's disease. J Alzheimers Dis 2016;53:1631-1640.

34 Amieva H, Robert PH, Grandoulier AS, Meillon C, De Rotrou J, Andrieu S, Joël ME; Group and individual cognitive therapies in Alzheimer's disease: the ETNA3 randomized trial. Int Psychogeriatr 2016;28:707-717.

35 Bahar-Fuchs A, Webb S, Bartsch L, Clare L, Rebok G, Cherbuin N, Anstey KJ: Tailored and adaptive computerized cognitive training in older adults at risk for dementia: a randomized controlled trial. J Alzheimers Dis 2017;60:889-911.

36 Buschert VC, Giegling I, Teipel SJ, Jolk S, Hampel H, Rujescu D, Buerger K: Long-term observation of a multicomponent cognitive intervention in mild cognitive impairment. J Clin Psychiatry 2012;73:e1492-e1498.

37 Coen RF, Flynn B, Rigney E, O’Connor E, Fitzgerald L, Murray C, Edgeworth J: Efficacy of a cognitive stimulation therapy programme for people with dementia. Irish J Psychol Med 2011;28:145-147.

38 Dawson D, Richardson J, Troyer A, Binns M, Clark A, Polatajko H, Winocur G, Hunt A, Bar Y: An occupationbased strategy training approach to managing age-related executive changes: a pilot randomized controlled trial. Clin Rehabil 2014;28:118-127.

39 Fernández-Calvo B, Contador I, Ramos F, Olazarán J, Mograbi DC, Morris RG: Effect of unawareness on rehabilitation outcome in a randomized controlled trial of multicomponent intervention for patients with mild Alzheimer's disease. Neuropsychol Rehabil 2015;25:448-477.

40 Förster S, Buschert VC, Teipel SJ, Friese U, Buchholz HG, Drzezga A, Hampel H, Bartenstein P, Buerger K: Effects of a 6-month cognitive intervention on brain metabolism in patients with amnestic MCI and mild Alzheimer's disease. J Alzheimers Dis 2011;26(s3):337-348.

41 Gagnon LG, Belleville S: Training of attentional control in mild cognitive impairment with executive deficits: results from a double-blind randomised controlled study. Neuropsychol Rehabil 2012;22:809-835.

42 Giovagnoli AR, Manfredi V, Parente A, Schifano L, Oliveri S, Avanzini G: Cognitive training in Alzheimer's disease: a controlled randomized study. Neurol Sci 2017;38:1485-1493.

43 Herrera C, Chambon C, Michel BF, Paban V, Alescio-Lautier B: Positive effects of computer-based cognitive training in adults with mild cognitive impairment. Neuropsychology 2012;50:1871-1881.

44 Huntley JD, Hampshire A, Bor D, Owen A, Howard RJ: Adaptive working memory strategy training in early Alzheimer's disease: randomized controlled trial. Br J Psychiatry 2017;210:61-66.

45 Kim HJ, Yang Y, Oh JG, Oh S, Choi H, Kim KH, Kim SH: Effectiveness of a community-based multidomain cognitive intervention program in patients with Alzheimer's disease. Geriatr Gerontol Int 2016;16:191-199.

46 Lam LC, Lui VW, Luk DN, Chau R, So C, Poon V, Tam P, Ching R, Lo H, Chiu J, Fung A, Ko FS: Effectiveness of an individualized functional training program on affective disturbances and functional skills in mild and moderate dementia - a randomized control trial. Int J Geriatr Psychiatry 2010;25:133-141. 
47 Law LL, Barnett F, Yau MK, Gray MA: Effects of functional tasks exercise on older adults with cognitive impairment at risk of Alzheimer's disease: a randomized controlled trial. Age Ageing 2014;43:813-820.

48 Luttenberger K, Hofner B, Graessel E: Are the effects of a non-drug multimodal activation therapy of dementia sustainable? Follow-up study 10 months after completion of a randomized controlled trial. BMC Neurol 2012; 12:151.

49 Mavros Y, Gates N, Wilson GC, Jain N, Meiklejohn J, Brodaty H, Wen W, Singh N, Baune BT, Suo C, Baker MK, Foroughi N, Wang Y, Sachdev PS, Valenzuela M, Fiatarone Singh MA: Mediation of cognitive function improvements by strength gains after resistance training in older adults with mild cognitive impairment: outcomes of the study of mental and resistance training. J Am Geriatr Soc 2017;65:550-559.

50 Mowszowski L, Hermens DF, Diamond K, Norrie L, Cockayne N, Ward PB, Hickie IB, Lewis SJ, Batchelor J, Naismith SL. Muñiz R, Serra CM, Reisberg B, Rojo JM, del Ser T, Peña Casanova J, Olazarán J: Cognitive training enhances pre-attentive neurophysiological responses in older adults "at risk" of dementia. J Alzheimers Dis 2014;41:1095-1108.

51 Muñiz R, Serra CM, Reisberg B, Rojo JM, del Ser T, Peña Casanova J, Olazarán J: Cognitive-motor intervention in Alzheimer's disease: long-term results from the Maria Wolff trial. J Alzheimers Dis 2015;45:295-304.

52 Ngandu T, Lehtisalo J, Solomon A, Levälahti E, Ahtiluoto S, Antikainen R, et al: A 2 year multidomain intervention of diet, exercise, cognitive training, and vascular risk monitoring versus control to prevent cognitive decline in at-risk elderly people (FINGER): a randomised controlled trial. Lancet 2015;385:2255-2263.

53 Olchik MR, Farina J, Steibel N, Teixeira AR, Yassuda MS: Memory training (MT) in mild cognitive impairment (MCI) generates change in cognitive performance. Arch Gerontol Geriatr 2013;56:442-447.

54 Rabey JM, Dobronevsky E, Aichenbaum S, Gonen O, Marton RG, Khaigrekht M: Repetitive transcranial magnetic stimulation combined with cognitive training is a safe and effective modality for the treatment of Alzheimer's disease: a randomized, double-blind study. J Neural Transm 2013;120:813-819.

55 Rojas GJ, Villar V, Iturry M, Harris P, Serrano CM, Herrera JA, Allegri RF: Efficacy of a cognitive intervention program in patients with mild cognitive impairment. Int Psychogeriatr 2013;25:825-831.

56 Schmitter-Edgecombe M, Dyck DG: Cognitive rehabilitation multi-family group intervention for individuals with mild cognitive impairment and their care-partners. J Int Neuropsychol Soc 2014;20:897-908.

57 Spector A, Charlesworth G, King M, Lattimer M, Sadek S, Marston L, Rehill A, Hoe J, Qazi A, Knapp M, Orrell M: Cognitive-behavioural therapy for anxiety in dementia: pilot randomised controlled trial. Br J Psychiatry 2015;206:509-516.

58 Suzuki H, Kuraoka M, Yasunaga M, Nonaka K, Sakurai R, Takeuchi R, Murayama Y, Ohba H, Fujiwara Y: Cognitive intervention through a training program for picture book reading in community-dwelling older adults: a randomized controlled trial. BMC Geriatr 2014;14:122.

59 Barban F, Annicchiarico R, Pantelopoulos S, Federici A, Perri R, Fadda L, Carlesimo GA, Ricci C, Giuli S, Scalici F, Turchetta CS, Adriano F, Lombardi MG, Zaccarelli C, Cirillo G, Passuti S, Mattarelli P, Lymperopoulou O, Sakka P, Ntanasi E, Moliner R, Garcia-Palacios A, Caltagirone C: Protecting cognition from aging and Alzheimer's disease: a computerized cognitive training combined with reminiscence therapy. Int J Geriatr Psychiatry 2016;31:340-348.

60 Buettner LL, Fitzsimmons S, Atav S, Sink K: Cognitive stimulation for apathy in probable early-stage Alzheimer's. J Aging Res DOI: 10.4061/2011/480890.

61 D'Onofrio G, Sancarlo D, Addante F, Ciccone F, Cascavilla L, Paris F, Elia AC, Nuzzaci C, Picoco M, Greco A, Panza F, Pilotto A: A pilot randomized controlled trial evaluating an integrated treatment of rivastigmine transdermal patch and cognitive stimulation in patients with Alzheimer's disease. Int J Geriatr Psychiatry 2015;30: 965-975.

62 Gaitán A, Garolera M, Cerulla N, Chico G, Rodriguez-Querol M, Canela-Soler J: Efficacy of an adjunctive computer-based cognitive training program in amnestic mild cognitive impairment and Alzheimer's disease: a single-blind, randomized clinical trial. Int J Geriatr Psychiatry 2013;28:91-99.

63 Jeong JH, Na HR, Choi SH, Kim J, Na DL, Seo SW, Chin J, Park SA, Kim EJ, Han HJ, Han SH, Yoon SJ, Lee JH, Park KW, Moon SY, Park MH, Choi MS, Han IW, Lee JH, Lee JS, Shim YS, Kim JY: Group-and home-based cognitive intervention for patients with mild cognitive impairment: a randomized controlled trial. Psychother Psychosom 2016;85:198-207.

64 Kolanowski A, Fick D, Litaker M, Mulhall P, Clare L, Hill N, Mogle J, Boustani M, Gill D, Yevchak-Sillner A: Effect of cognitively stimulating activities on symptom management of delirium superimposed on dementia: a randomized controlled trial. J Am Geriatr Soc 2016;64:2424-2432.

65 Niu YX, Tan JP, Guan JQ, Zhang ZQ, Wang LN: Cognitive stimulation therapy in the treatment of neuropsychiatric symptoms in Alzheimer's disease: a randomized controlled trial. Clin Rehabil 2010;24:1102-1111.

66 Orgeta V, Leung P, Yates L, Kang S, Hoare Z, Henderson C, Whitaker C, Burns A, Knapp M, Leroi I, Moniz-Cook ED, Pearson S, Simpson S, Spector A, Roberts S, Russell IT, de Waal H, Woods RT, Orrell M: Individual cognitive stimulation therapy for dementia: a clinical effectiveness and cost-effectiveness pragmatic, multicenter, randomized controlled trial. Health Technol Assess 2015;19:1-108.

67 Polito L, Abbondanza S, Vaccaro R, Valle E, Davin A, Degrate A, Villani S, Guaita A: Cognitive stimulation in cognitively impaired individuals and cognitively healthy individuals with a family history of dementia: shortterm results from the "Allena-Mente" randomized controlled trial. Int J Geriatr Psychiatry 2015;30:631-638. 
68 Quintana-Hernández DJ, Miró-Barrachina MT, Ibáñez-Fernández IJ, Pino AS, Quintana-Montesdeoca MP, Rodríguez-de Vera B, Morales-Casanova D, Pérez-Vieitez Mdel C, Rodríguez-García J, Bravo-Caraduje N: Mindfulness in the maintenance of cognitive capacities in Alzheimer's disease: a randomized clinical trial. J Alzheimers Dis 2016;50:217-232.

69 Van Haitsma KS, Curyto K, Abbott KM, Towsley GL, Spector A, Kleban M: A randomized controlled trial for an individualized positive psychosocial intervention for the affective and behavioral symptoms of dementia in nursing home residents. J Gerontol B Psychol Sci Soc Sci 2013;70:35-45.

70 Han JW, Lee H, Hong JW, Kim K, Kim T, Byun HJ, Ko JW, Youn JC, Ryu SH, Lee NJ, Pae CU, Kim K: Multimodal cognitive enhancement therapy for patients with mild cognitive impairment and mild dementia: a multicenter, randomized, controlled, double-blind, crossover trial. J Alzheimers Dis 2017;55:787-796.

71 Prince M, Wimo A, Guerchet M, Ali GC, Wu YT, Prina M: World Alzheimer Report 2015 - The Global Impact of Dementia: An Analysis of Prevalence, Incidence, Cost and Trends. London, Alzheimer's Disease International, 2017. 